Año 9. Núm. 24 (Edición especial julio- diciembre 2016)

http://revistainvestigacionacademicasinfrontera.com
Revista de Investigación

Académica sin Frontera

ISSN: 2007-8870

Recibido el 22 de junio de 2016.

Dictamen favorable el $\mathbf{2 0}$ diciembre de 2016.

\title{
DERECHOS HUMANOS, LA PAZ Y CIUDADANIA DESDE LA OPTICA UNIVERSITARIA.
}

\author{
L.E. María Antonieta Silva Valenzuela \\ tone@navojoa.uson.mx \\ L.E.I. Rosa Gabriela Guadalupe Ochoa Silva. \\ Gaby.1291@hotmail.com
}

\section{INTRODUCCION}

Tomando en cuenta las esferas de reconocimiento en la teoría de Axel Honneth (Hernán, 2011). Se encuentran las esferas del reconocimiento principalmente del derecho que es en esta esfera universal donde los seres humanos se reconocen como fuente de deberes y derechos, independientemente de toda caracterización de orden social, económico y cultural, y un cumulo de valores de la sociedad que puede propiciar que los nuevos grupos luchen por su reconocimiento ya que lo peor que les pueden hacer a los humanos es discriminarlos y lastimar su integridad social (autorrespeto)., en cambio la paz se encuentra dentro de la esfera de la solidaridad la cual es contextual, cada sociedad tiene sus propios valores, busca cualidades y capacidades, es la relación en la que los sujetos se reconocen entre si, es decir que necesitan de afectos, la cual puede ser simétrica o asimétrica y esto a su vez tiene que ver con el amor. Es por esto que es muy importante esta interrelación porque la paz busca tranquilidad, y reforzar su autoestima .

La realidad tiene que transformarse a través de los derechos humanos o a través de la paz, aunque siempre habrá tensión permanente para hacer valer los derechos 


\section{(Edición especial julio-diciembre 2016)}

\section{http://revistainvestigacionacademicasinfrontera.com}

Revista de Investigación

Académica sin Frontera ISSN: 2007-8870

o para lograr la paz. Se tiene que conocer la realidad social y modificarla desde lo particular a lo universal.

Y la pedagogía critica pretende que el alumno universitario logre cambiar las practicas represivas para generar respuestas liberadoras dentro del proceso social que se está viviendo como lo es la cultura, la identidad, la religión ,dándose cuenta que la sociedad es imperfecta y trate de modificar su realidad social para esto es muy importante la educación que recibe el alumno en la institución educativa. Es por esto que se propone que sean los alumnos los que salgan a impartir cursos y talleres en sus colonias para que enseñen lo que son los derechos humanos y la paz para que vivan y se desarrollen mejor los ciudadanos.

Punto no uno, En cuanto a los Derechos Humanos, se pueden encontrar una serie de conceptos sobre los derechos humanos, ¿Qué son?, ¿Cómo están constituidos?, La historia etc.

A conocer más a fondo ¿Para qué nos sirven?, ¿Cómo podemos utilizarlos?.

En sí los derechos humanos son el conjunto de prerrogativas sustentadas en la dignidad humana, cuya realización efectiva resulta indispensable para el desarrollo integral de la persona.

Es algo que obtenemos al nacer y conforme vamos creciendo van creciendo con nosotros por ejemplo el derecho a tener una vivienda digna, a la educación, a la salud etc. $Y$ todo lo que ocupemos hasta nuestra muerte.

Punto número dos. También encontrara en este trabajo que la Paz es un tema bastante interesante para los universitarios, el no vivir en una paz permanente implica, estar en intranquilidad, no ser productivo, conflictos, estress, problemas familiares todo esto es por el contexto en el que se vive, existen muchos 


\section{http://revistainvestigacionacademicasinfrontera.com}

Revista de Investigación

Académica sin Frontera

ISSN: 2007-8870

accidentes, drogadicción, muerte de jóvenes, la corrupción, alcoholismo y muchos otros problemas sociales que hacen que la vida no tenga sentido ni en jóvenes ni en adultos, también lo son los problemas de los sistemas educativos, las muertes de los alumnos en Ayotzinapa, de los maestros de Michoacán, de los maestros de Chiapas, etc. por citar algunos ejemplos de nuestro país aunque hay otros que se presentan por la globalización como son la pobreza de Africa, el conflicto generado por la religión de los sirios, y un sinfín de problemas. Generados por el multiculturalismo respondiendo a la política de cada país y por esto mismo es imposible que exista la paz al cien por ciento porque cada quien tiene sus intereses muy particulares, aunque también existen quienes buscan participar en los colectivos, la cultura de paz intenta acabar con todas las amenazas que van desde la falta de respeto por los derechos humanos, la justicia y la democracia hasta la pobreza o la ignorancia.

En la Universidad de Sonora se fomentan los valores como la honestidad el respeto, la tolerancia, responsabilidad social, ética, solidaridad, justicia, compromiso con la naturaleza, el fin de fomentar estos valores es con el fin de incrementar la cultura de la paz tanto en la Universidad como en el Estado e Sonora porque "el saber de mis hijos hará mi grandeza" no solo se refiere al conocimiento sino a las personas que forja día a día para ser mejores personas y profesionistas.

Lograr una cultura de paz es hacer que tanto niños como adultos comprendan y respeten la libertad, la justicia, la democracia, los derechos humanos, la tolerancia, la igualdad y la solidaridad, ello implica un rechazo a la violencia y busca el participar activamente en el desarrollo de la sociedad., ya lo decía (Tajonar, 3 de julio 2016) en cualquier caso la violencia es totalmente ajena al derecho humano fundamental de más de 30,000,000 de alumnos a recibir una educación de calidad , e igualmente contraria al interés nacional, hoy más que nunca el futuro educativo 


\section{(Edición especial julio- diciembre 2016)}

\section{http://revistainvestigacionacademicasinfrontera.com}

Revista de Investigación

Académica sin Frontera ISSN: 2007-8870

del país está hundido en un mazacote de ambiciones políticas torcidas, esto es contradictorio a lo que las universidades buscan inculcar a sus alumnos.

El tercer punto es la ciudadanía y por esto comentamos que al ingresar a la Universidad los alumnos ya son todos unos ciudadanos, y es claro que para que exista una ciudadanía debe existir un ciudadano pero en que sentido entendemos ¿Qué es un ciudadano? Y de qué manera se diferencia el termino ciudadano de ciudadanía.

Un ciudadano responsable es caracterizado por:

- Se sentido de pertenencia, sabe de dónde viene, en donde se encuentran sus raíces.

- Participación en los procesos de elección de las autoridades, ejerciendo su derecho al voto.

- Cumple las leyes y normas que rigen la convivencia social.

- Es amable y procura los buenos modales.

- Paga los impuestos y promueve y exige transparencia en el buen uso de los bienes.

- Participa identificando problemas y proponiendo soluciones.

- Actúa bajo principios de respeto y tolerancia a la pluralidad y diversidad.

\section{OBJETIVOS}

- Un objetivo de este trabajo es: Dar a conocer los Derechos Humanos a las personas que no tienen acceso a la información de las leyes que imperan en nuestro país, para que puedan defenderse de las injusticias que valiéndose 
http://revistainvestigacionacademicasinfrontera.com de esas leyes, abusan y se burlan de los derechos, aunque no sea la persona ignorante solo lo hacen porque abusan del poder y pueden hacerlo y se sienten invencibles.

- Otro de los objetivos es, tomar en cuenta que en los días actuales la sociedad tiene diversos problemas los cuales son sencillos o pueden ser más profundos, logrando con esto la inestabilidad, por lo cual es necesario que se respete la opinión, pensamientos y creencias de cada persona. Entonces, el objetivo primordial de los universitarios es promover la paz a travez de cursos y talleres entre los mismos estudiantes y cada estudiante entre su familia como parte de la sociedad y al mismo tiempo se les explicara en que consiste la ciudadanía.

- Pregunta: ¿Podremos los universitarios entender bien lo que son los Derechos Humanos, la Paz y la Ciudadanía como para poder transmitir nuestros conocimientos a las personas con las que convivimos $y$ lograr tener paz en ese lugar que donde habitamos, trabajamos, convivimos con las demás personas? ¿ Cómo evitar que pisoteen mis derechos ?¿ La violencia ocupa de un tercero para resolverse?

\section{LOS DERECHOS HUMANOS EN LA HISTORIA}

El origen de los derechos humanos en el siglo xviii en occidente, cuando se confortaron nuevamente los valores "globales" y los orientales hacia 1760 a. C se hizo el primer esfuerzo mediante la creación del código de Hammurabi. 


\section{http://revistainvestigacionacademicasinfrontera.com}

Gracias a él se clasifico la necesidad de generar leyes formales que incluyeran la protección del ser humano. El código defendía los derechos de propiedad y vida.

Asimismo preveía la protección a la vida familiar para lo que se establecían castigos para el adulterio y por el incumplimiento de la estabilidad material de la familia por parte del hombre.

La libertad de expresión se convirtió, a finales del siglo xviii. En su declaración de los derechos del hombre y el ciudadano (1789) la revolución francesa hizo explicita la defensa del derecho a expresarse.

La lista de derechos básicos comenzó a crecer, la educación infantil, que limitaba el trabajo a menores en fábricas, con lo que se redefinió lo que se entendía por infancia, la asistencia a la escuela por lo menos a un nivel básico se hizo obligatoria.

Durante la segunda guerra mundial, los nazis restablecieron el sistema de esclavitud con mano de obre judía. Esta vuelta a la violación constante de los derechos entre 1914 y 1945 dio origen a la organización de las naciones unidas concentrándose en la defensa de los derechos humanos.

La declaración incluía diversas discusiones que se venían siguiendo en años pasados: se prohibían la discriminación por raza, género, religión y nacionalidad. El matrimonio debía ser mutuo acuerdo, también se debía garantizar la libertad de pensamiento religión, expresión y de reunión.

En 1966 la ONU planteo un convenio sobre derechos civiles y políticos, que fue firmado por varios miembros pero que tuvo efecto una década después y algunos firmaron con excepciones específicas. (Gomez Johnson, 2014 ) 
http://revistainvestigacionacademicasinfrontera.com

De acuerdo a la COMISION DE DERECHOS HUMANOS, Son el conjunto de prerrogativas sustentadas en la dignidad humana, cuya realización efectiva resulta indispensable para el desarrollo integral de la persona.

El respeto hacia los derechos humanos de cada persona es un deber de todos. Todas las autoridades en el ámbito de sus competencias, tienen la obligación de promover, respetar, proteger y garantizar los derechos humanos consignados en el favor del individuo.

Los derechos humanos se rigen por los siguientes principios:

Principio de la universalidad: señala que lo derechos corresponden a todas las personas por igual.

Principio de la interdependencia: consiste en que cada uno de los derechos humanos se encuentran ligados unos a los otros, de tal manera que el reconocimiento de cada uno de ellos, así como su ejercicio, implica necesariamente que se respeten y protejan múltiples derechos que se encuentran vinculados.

Principio de la indivisibilidad: posee un carácter indivisible pues todos ellos son inherentes al ser humano y derivan de su dignidad.

Al igual. (Garcia Ramirez) Este autor nos dice que los derechos humanos son exigencias éticas que expresan necesidades vitales y son resultado de luchas históricas que propugnan por generar una "cultura de los derechos humanos" y por su reconocimiento y tutela por parte del estado.

De acuerdo a (Ruiz Rodriguez , 2007) dice que los derechos humanos se utilizan en muchos términos: libertades individuales, derechos subjetivos, derechos naturales, derechos del hombre, derechos humanos, libertades públicas, valores morales, derechos individuales, derechos fundamentales. 


\section{(Edición especial julio- diciembre 2016)}

\section{http://revistainvestigacionacademicasinfrontera.com}

Revista de Investigación

Académica sin Frontera ISSN: 2007-8870

Según (Vidigal De Oliveira., 2011 ) Esta categoría de derechos mínimos del hombre, la cual se ha convenido identificar como derechos humanos, y que se traduce en un lengua común de la humanidad constituye, así, un tema que hace más de medio siglo viene despertando especial atención en la sociedad internacional, con la adopción de constantes medidas para su tratamiento específico y diferenciado

Las creencias permiten entender como predecir y guiar el comportamiento porque intervienen en la selección de herramientas cognitivas para el procesamiento de la información, la organización del conocimiento y la toma de decisiones. En ese sentido la información y las creencias que los estudiantes sostengan sobre los derechos humanos influirán en su modo de actuar con respecto a ellos y en la manera en que se reciba y se procesa la información de cualquier intervención educativa (Vilches Choquehuayt \& Ffisancho, 2013)

Por lo tanto el conocimiento previo que los jóvenes universitarios tienen sobre los derechos humanos influye en la forma en que estos ven los valoran y aprecian así como la forma de exigirlos hacerlos valer y respetarlos tanto los propios como los de otras personas.

El ser humano ocupa tener educación y formación en valores

\section{En la guía básica de derechos universitarios se observa lo siguiente:}

Mandato actual:

- Objeto: Defensa de los derechos de la comunidad universitaria académicos, administrativos y estudiantes.

- Resolución de problemáticas: legislación universitaria, tutela de derechos, problemas individuales. 
http://revistainvestigacionacademicasinfrontera.com

- Facultades: recepción de quejas, emisión de recomendaciones no vinculatorias, mediación.

- Importancia: Identificación y resolución de problemáticas estructurales y abusos al interior de la comunidad universitaria.

(NIEBLAS PICOS , 2015, 2 DE SEPTIEMBRE DE 2016)

De los DERECHOS UNIVERSITARIOS siguiendo con Nieblas Picos se entiende que La Comisión Nacional de Derechos Universitarios está facultada para intervenir a petición de parte o de oficio, en aquel derecho inherente a tu libertad y dignidad y persona son: el respeto, tolerancia, la diversidad y la equidad entre nosotros.

Dentro de los derechos universitarios se puede mencionar el estímulo (art. 57,58 y $59\}$ otorgado a los alumnos para fomentar la excelencia académica, al igual que las responsabilidades (art. 65,66,67 y 68) que tienen los alumnos para no promover la suspensión de actividades académicas o administrativas, otra responsabilidad es no dañar o destruir los bienes de la universidad y se observa también en la guía básica de los derechos universitarios el reglamento escolar que tiene que ver con los derechos y obligaciones (art.19,20 y 21), existe un apartado acerca de las evaluaciones (art. Del 68 al 81), así mismo contiene un reglamento de cuotas, otro de servicio social, otro de servicios gratuitos para estudiantes, otro de becas ayudantía y programas de becas.

\section{EDUCACION PARA LOS DERECHOS HUMANOS.}

Las personas no están aisladas, en el mundo por lo que el futuro de la educación deberá garantizar culturalmente el reconocimiento y comprensión de la igualdad de cada una en la sociedad y el trabajo para buscar una vida mas digna y lograr su desarrollo humano. 
http://revistainvestigacionacademicasinfrontera.com

En la Universidad de Sonora es claramente observable una cultura de respeto y tolerancia entre estudiantes y esto es especialmente importante ya que refleja una convivencia sana entre los alumnos.

Aprender significa adaptarse, cooperar y transformar el entorno. Es el proceso mediante el cual los cuerpos dialogan, proponen y disponen y, por ello, constituye el principio organizador de toda sociedad y de toda biología... El aprendizaje es un factor de vida. (Muñoz, 2014) Es por la importancia del aprendizaje que debió comenzar el cumplimiento del derecho a la educación. El aprendizaje es el medio por el cual los sujetos logran integrarse a una sociedad, adquirir la capacidad de autorreflexión y en el ejercicio de ésta aptitud se vuelve más sencilla la empatía por las personas que nos rodean.

Se puede señalar que la situación de nuestra universidad no se encuentra dentro de un contexto donde predomine la conducta social que enaltezca a la figura masculina. Tanto hombres como mujeres son respetados y tomados en cuenta por igual. Por ejemplo, a ambos (hombre y mujer) se les brinda por igual la oportunidad de matricularse en cualquiera de los campus del estado, la calificación se logra por igual y el acceso escolar no es motivo ni de exclusión ni de discriminación.

En México, algunas escuelas han sido vulneradas por la criminalidad y la violencia, lo que genera una dinámica inédita que impone a los colectivos escolares el desafío de desplegar una respuesta pertinente con pocos referentes y pobres orientaciones. (Conde Flores, 2014)

La enseñanza dentro del marco comprensivo de los derechos humanos ofrece una nueva forma de ver la sociedad para aquellos que desconocen de sus derechos y los de los de los demás, que sus relaciones con quienes representan para ellos una autoridad y el reconocimiento de sus obligaciones frente a ésta. 
http://revistainvestigacionacademicasinfrontera.com

\section{EDUCACION DE CALIDAD PARA TODOS}

Los pueblos de américa latina acosados por la reciente pobreza, forman parte de esa realidad mundial. Las cifras parecen apoyar esa percepción un reciente informe de la comisión Económica para América latina señala que la globalización y las reformas que esta ha impuesto esta tiene como resultado $44 \%$ latinoamericanos pobres y un 30\% en riesgo de caer en la pobreza (VARGAS DE AVELLA , 2007)

De acuerdo con Vargas de Avella cuando menciona lo que es el valor más importante en relación con la educación en la actualidad y este viene siendo el valor de la equidad siendo esta la principal, la finalidad de los derechos humanos educativos que con el paso de los años han tratado de formar una educación igualitaria de calidad y ética para el desarrollo de la sociedad en general.

\section{CIUDADANIA}

La ciudadanía es un tema muy importante para las ciencias Sociales y Humanas, de acuerdo con el Dr. José Carlos García Ramírez, La ciudadanía es la entidad política que en una democracia faculta a la persona y a los grupos para llevar sus demandas de la vida cotidiana al ámbito de lo público haciendo posible su participación política democrática; está constituida por una comprensión política democrática, un lenguaje político democrático y unas practicas políticas democráticas que suponen en la persona el desarrollo de competencias civicas, es la dimensión subjetiva de la cultura política democrática.

De acuerdo a Espinoza Mario, 2008 "la participación ciudadana es un concepto regularmente empleado para designar un conjunto de procesos y prácticas sociales de muy diversa índole de aquí el problema o la riqueza de su carácter polisémico. Problema porque la pluralidad de significados en ciertos momentos, ha conducido a un empleo analítico bastante ambiguo, riqueza porque la multiplicidad de nociones mediante las que se ha enunciado ha permitido acotar cada vez con 


\section{(Edición especial julio- diciembre 2016)}

\section{http://revistainvestigacionacademicasinfrontera.com}

Revista de Investigación

Académica sin Frontera ISSN: 2007-8870

mayor precisión, los actores, espacios y variables involucradas, así como las características relativas a la definición de este tipo de procesos participativos"

Historia ciudadana.

cada uno de los seres humanos hacían cosas por su cuenta se decidió que aquellos seres que estaban solos necesitaban un líder, el líder era quien les daría ordenes, poco a poco ese líder se unió con otro conjunto de seres que tenían exactamente el mismo problema, la historia se repitió y los seres cada vez tenían más líderes y los otros seres (Inferiores) solo eran dominados por aquellos seres líderes, los seres se establecieron en ciertas áreas geográficas y las adaptaron a ellas, y así se fue creando la sociedad, cada sociedad implemento un reglamento que debía ser cumplido si no serían castigados (Sancionados), cuando existían conflictos con otras sociedades, los seres de rango más bajo tenían que resolverlo, dando su vida por una "Patria" las historias se repiten y se repiten se crean guerras donde los soldados pelean en nombre de un país o de una ideología el que gana la guerra es quien tenía la razón, dan su vida por el respeto de cierto país o ideología convirtiéndose en un mártir, algunas guerras han tenido buenos ideales, principalmente las guerras donde se juega la independencia de un país, pero hay otras que solo por la avaricia de los mandatarios donde muere gente inocente por el capital de una nación o el bolsillo de algunas personas.

Acaso fue necesario que cristo muriera en la cruz para entender su mensaje de amarnos los unos a los otros, o acaso fue necesario que encerraran a Mandela para entender que los negros también tienen voz, los ciudadanos como los estados tenemos obligaciones, pero también tenemos derechos y nadie debe morir por pensar diferente al resto, mucho menos si esa idea busca solucionar un problema. 


\section{(Edición especial julio- diciembre 2016)}

http://revistainvestigacionacademicasinfrontera.com
Revista de Investigación

Académica sin Frontera ISSN: 2007-8870

"La ciudadanía implica la relación entre el individuo, el Estado y la sociedad y, por consiguiente tiene que ver tanto con Derechos como con deberes relacionados con la participación de las esferas públicas" (Vidrio)

El concepto de ciudadanía a adquirido nuevos términos y condiciones según en la sociedad en que se ha ido ejerciendo.

De acuerdo con ( Giraldo-Zuluaga,2015,) "fue quien definió la ciudadanía como un estatus (estado, posición, condición) que se concede a los miembros de pleno derecho de una comunidad. Pero para que fuera real, plena, debía integrar tres tipos de ciudadanía: una ciudadanía civil (que comprende los derechos y las libertades individuales), una ciudadanía política (que contiene los derechos políticos) y una ciudadanía social (que abarca todos los derechos económicos, sociales y culturales)"

También dice que la actualidad se plantea que la ciudadanía contiene 3 dimensiones:

- Titularidad: La ciudadanía tiene derechos y deberes.

- Condición política: Permite al ciudadano actuar en decisiones políticas.

- Identidad o pertenencia: El ciudadano tiene el derecho a pertenecer a una entidad y adoptar sus rasgos culturales.

La ciudadanía se ejerce mediante:

- Votación de las elecciones.

- Unirte voluntariamente a trabajos comunitarios.

- Contribuir a las ideologías políticas.

- Exigir al Estado por sus deberes.

- Cumplir con las obligaciones que nos impone el Estado. 


\section{http://revistainvestigacionacademicasinfrontera.com}

La ciudadanía es una gama de posibilidades, y técnicamente es la forma básica de vivir, la ciudadanía aquí en México ha ido decayendo cada vez más por culpa del Estado como del ciudadano.

Por parte del Estado porque no ayuda a cumplir con las obligaciones o con los reclamos de ciertas comunidades, y por parte del ciudadano al no cumplir con las obligaciones que nos impone el Estado.

Dando una vista al pasado podemos ver que fallas hemos tenido como ciudadanos mexicanos y de igual manera podemos ver que fallas tiene el estado,

También se debe aclarar que ciudadanía no es lo mismo que nacionalidad porque:

"La nacionalidad es una especial condición de sometimiento político de una persona a un Estado determinado, sea por haber nacido en su territorio, sea por descender de padres naturales de ese Estado, sea por haber convenido voluntariamente en sujetarse políticamente a él. La ciudadanía, en cambio, es la calidad que adquiere el que, teniendo una nacionalidad y habiendo cumplido las condiciones legales requeridas, asume el ejercicio de los derechos políticos que le habilitan para tomar parte activa en la vida pública del Estado y se somete a los deberes que le impone su calidad." (Lizcano Fernández, 2012)

"Está claro que no puede haber ciudadanía sin nacionalidad, puesto que esta es condición necesaria para aquella, pero sí puede haber nacionalidad sin ciudadanía, "como en el caso de los menores de edad o de los adultos interdictos por cualquier causa, que pertenecen al Estado pero que no tienen el uso de los derechos políticos" (Giraldo-Zuluaga, 2015,) 


\section{http://revistainvestigacionacademicasinfrontera.com}

Como ciudadanos tenemos que entender que el objetivo es la paz social, el ciudadano al ser parte de una ciudadanía tiene derechos, y obligaciones, debemos entender que para poder vivir en paz el respeto es fundamental, porque mis derechos empiezan donde el del otro termina, es algo fundamental entender en que consiste todo este sistema, la educación es importante en nuestra sociedad, son los alumnos parte de esa importancia ya que son estudiantes, del futuro y a la vez del presente de la nación.

En nuestra ciudad hay una infinidad de fallas, donde los únicos dañados somos los ciudadanos y creando daños colaterales a los estudiantes, parece que no, pero los hechos delictivos van en aumento, el desempleo y la falta de interés de los ciudadanos va creciendo al igual que el desempleo, la inmigración hacia otros lugares es algo normal en nuestra ciudad, como estudiantes exigen y hacen valer su voz y enseñarle a la sociedad en que consiste la ciudadanía, como ser mejores ciudadanos, pero más que nada abrirles los ojos porque el Estado solo quiere mantener a una comunidad ignorante, y desinformada y por supuesto también la comunidad hace su aportación para redondear su propia sumisión: aporta su apatía, su desinterés y no cuestiona aunque intuye que las cosas están mal, no lo hace porque su ignorancia es tal, que no sabe ¿qué cuestionar? Y

¿ cómo hacerlo? o porque tienen miedo entonces solo se conforma con existir, la comunidad debe asumir el rol, para equilibrar la fuerza del poder; porque si este se queda del lado de quien lo gobierna, el resultado es una dictadura, y si se queda del lado de la comunidad se genera una anarquía.

\section{LA PAZ}

Es en general un estado de quietud y tranquilidad, y en sentido opuesto como ausencia de inquietud, violencia o guerra. 


\section{http://revistainvestigacionacademicasinfrontera.com}

De acuerdo con (Martinez Real, 2012) el proceso educativo tiene grandes retos motivo por el cual la transversalidad se plantea como una estrategia de diseño curricular que debe alcanzar uno de los mayores retos de la educación , la formación integral del alumno, partiendo de esta idea los ejes transversales deben ser considerados como claves de la misma. Por lo tanto la educación para la paz es una de esas claves de la formación integral del alumno.

Para los docentes esto es más bien un reto, es una oportunidad de desarrollo de la capacidad y potencial del estudiante para lo cual es necesario conocer conceptos básicos como son los términos históricos en los que se han dado tres maneras de estudiar el concepto de la paz.

Primera etapa Paz negativa;(ausencia de violencia directa, falta de conflictos armados )

Segunda etapa: Paz positiva: (ausencia de violencia estructural)

tercera etapa: Paz neutra (ausencia de violencia cultural y/ o simbolica).

Y más que nada el relacionar la materia que se imparte con la paz, utilizar películas que los hagan reflexionar, la solidaridad y el trabajo en equipo. Esto lo debe hacer educando con amor, paciencia, delicadeza, cuidado y atención.

Para lograr no mejorar sus calificaciones como metas, sino ser una persona con compromisos morales y éticos. Para ser libre y autónomo, listo para reconocer que la paz es la construcción de la justicia y . que no amenazara ni formara personas pasivas entendiendo que el concepto de paz y guerra están ligados. Asi como también se dice que si no hay crisis no hay crecimiento., violencia y paz van paralelos 


\section{(Edición especial julio- diciembre 2016)}

\section{http://revistainvestigacionacademicasinfrontera.com}

Revista de Investigación

Académica sin Frontera ISSN: 2007-8870

"Educar para la paz y la convivencia es un objetivo defendido con ahínco por todos los sectores de la comunidad educativa. No sólo en el futuro, sino también en el presente dependen de que nuestros niños, adolescentes y jóvenes aprendan a resolver sus conflictos por vías pacíficas” Jiménez Bautista,2009.

Desde nuestro punto de vista, la neutralidad es la base de toda relación social ya que con el respeto al «otro» se desvalorizan las distintas formas de violencia (directa, estructural y cultural y/o simbólica).

Por ejemplo, ¿Cómo se justificó la esclavitud de los negros en EE. UU. en el siglo XIX? Por la supuesta inferioridad de la raza. ¿Cómo se justificó la muerte de los judíos por parte del régimen nazi? Por la inferioridad de la raza. Porque el equívoco en que se encuentra la cultura islámica supone un peligro para la humanidad.

La paz neutra según (Jimenez Bautista , 2009) debe ser entendida como un concepto que posee un potencial mayor cuando pensamos que vale tanto para las relaciones personales como en lo macro-social. Es decir, no es sólo intentar establecer un diálogo igualitario entre grandes culturas, sino procurar que la convivencia cotidiana se asiente en valores como la empatía, la tolerancia, la diversidad, la solidaridad, etc.

\section{CONFLICTOLOGÍA}

Conflictología o Resolución de Conflictos, es la ciencia del conflicto, contiene los conceptos de crisis, cambio, violencia o problema. Según (Vinyamata, 2015) Sin comprensión de los conflictos poco podremos hacer para que estos se reduzcan o se transformen en oportunidades de mejorar. Ya que los conflictos, la ausencia de paz y la armonía son el pan de cada dia,ya sea individual o colectivamente y los 


\section{http://revistainvestigacionacademicasinfrontera.com}

humanos enfrentamos esta situación a cada instante donde se genera la violencia al no buscar solución a sus problemas, ya que no entienden el origen y las causas que .lo generan. Esta es la razón de la importancia, la Conflictología incluye aportaciones de la Sociología, Antropología, Psicología, y Neurología (emociones)

Buena parte de los esfuerzos de la Humanidad han consistido y consisten en aprender a resolver conflictos, garantizar la seguridad y vivir en paz.

Se tiene que tener disposición y buscar de alguna manera en aprender a resolver sus conflictos por métodos pacíficos, tranquilos para poder vivir con tranquilidad

A veces se comete el error de combatir la violencia con más violencia y esto es cuento de nunca acabar, no trae nada bueno no es la fuerza física ni las armas lo que puede resolver conflictos y a través de la conflictología se pretenden resolver los problemas con soluciones satisfactorias y sin violencia, al igual que la mediación que es otra forma de buscar la cultura del dialogo y la paz en las relaciones interpersonales, evitando la intervención de los profesionales del Derecho que a veces en lugar de ayudar dañan más la situación juzgando al resolver.

\section{LA ESCUELA DEL FUTURO}

La educación para la paz será uno de los objetivos prioritarios de la escuela del futuro. La educación del siglo XXI, afirma la Comisión Internacional de la UNESCO, Delors J. (1996) sobre la educación, debe apoyarse en cuatro pilares básicos: aprender a conocer, aprender a hacer, aprender a vivir con los demás y aprender a ser. 
http://revistainvestigacionacademicasinf rontera.com

\section{CONCLUSIONES Y PROPUESTAS}

"EL MUNDO DE LA VIDA COTIDIANA ES UN MUNDO SIMBOLICO SE DESARROLLA EN EL MARCO DE LOS SIMBOLOS SAGRADOS Y PROFANOS PERO TAMBIEN DE LOS SIMBOLOS QUE CREAN LAS INSTITUCIONES, IOS ciudadanos comunes es probable que no le demos importancia a lo que tenemos al alcance de nuestra vista., a lo que nos rodea es la rutina, lo cotidiano, lo normal. ¿Qué estamos haciendo para nosotros en lo personal? (Quiroz miranda, 2016)

Sin embargo y hablando de paz leer libros que hablan sobre lo mismo pero que presentan letras llenas de dolor de acuerdo a (Le Barón, Julian;, 2016) Quedarnos callados es como validar una golpiza que le están dando a alguien enfrente de nosotros, no hacer nada frente a la violencia es estar de acuerdo con la violencia.........incluso aun acabando con el narcotráfico la violencia seguirá. Si en nuestra indiferencia perdemos la compasión, la humanidad y la conciencia del otro, la violencia seguirá...... Hermanos y hermanas la responsabilidad de acabar con la violencia está en nosotros.

De acuerdo con (Mejía Jiménez , 2014) "Es necesario construir las propuestas en la esfera de lo educativo y lo pedagógico, que concreten la lucha de una nueva sociedad en el día a día de la práctica pedagógica,, entendida esta como los saberes propios de toda acción educativa. Por ello dimensiona el conflicto y la lucha social en las particularidades del quehacer educativo, en sus dimensiones, micro, macro y meso dando forma a la acción critica en la esfera de las subjetividades la acción de enseñar, los procesos institucionales, los impactos de lo educativo y pedagógico en los territorios, localidades y en las esferas nacionales e internacionales, asi como en los nuevos escenarios masivos y tecnológicos." Esto es luchar por la transformación y la emancipación social, cultural y económica. 


\section{http://revistainvestigacionacademicasinfrontera.com}

Revista de Investigación

Académica sin Frontera ISSN: $2007-8870$

Es muy importante el desarrollo del dialogo, debe ser abierto. Se debe trabajar y usar como método el dialogo o dialógico donde el lenguaje es la base de la comunicación humana. y se deben generar nuevas ideas utilizando el pensamiento crítico con educación en valores en derechos humanos, que son valores universales, así como la cultura por la paz, y la ciudadanía.

sin embargo la violencia y la guerra son dos situaciones que siempre estarán presentes por la misma situación de la globalización y la competencia de poder por eso es muy importante enseñar, programar, desarrollar cursos y talleres entre los universitarios para que difundan desde su entorno a conservar la paz y no actuar con violencia a cualquier provocación , a aprender a manejar su emoción y no responder con golpes ni con su fuerza física abusando de los débiles.

Como ya lo mencionamos, son muchos factores que pueden afectar la paz en nuestras vidas. El estress, la inseguridad jurídica, laboral etc.

No solo es crear enseñanza en las universidades de los valores, también se deben buscar métodos que resuelvan los conflictos sin violencia.

En la Universidad de Sonora tenemos alumnas que no tienen paz porque están casadas y su familia y/o esposo no las apoyan para seguir superándose esto les genera frustraciones por la violencia de genero presentada, y no pueden a veces comprender cosas muy sencillas por su misma preocupación y se afecta la educación

También tenemos alumnos foráneos, que el tiempo está en su contra y tienen que salir de sus hogares hasta 2-3 horas antes para poder llegar a tiempo a sus clases. Esto crea un sentimiento de frustración porque además causa conflictos económicos al utilizar otro servicio, y temor de que los asalten en el transcurso de la universidad a su casa. 


\section{http://revistainvestigacionacademicasinfrontera.com}

Revista de Investigación

Académica sin Frontera ISSN: $2007-8870$

Hay alumnos y alumnas con hijos y en muchas ocasiones su responsabilidad de padres les impide llegar a clases, porque evidentemente los tienen que cuidar, esto crea que no tengan la seguridad de asistir a sus estudios o que los reprueben por faltas o no tener el trabajo seguro para alimentar a sus niños. $Y$ no hay suficientes becas para que los apoye la institución o el gobierno, es la misma pobreza generada por el estado y recae sobre los estudiantes.

La inseguridad en nuestra localidad es un problema muy grande, porque aunque nuestros jóvenes vivan a la vuelta de la esquina se vive con la inseguridad de algún asalto, una balacera y pueden llegar a salir lastimados por el simple hecho de ir pasando por ahí. No solo las grandes guerras generan estrés y ausencia de paz.

El ciudadano lucha por el día a día resignado a su vida donde los mayores placeres que puede encontrar es en comer, ver tv., trabajar para que cada fin de semana se emborrache tirando toda una semana de esfuerzo en algunas horas de felicidad, este viene siendo un aspecto cultural, aquí tiene el ciudadano un papel muy importante a seguir porque se dice que la democracia es una construcción cultural.

Entonces el estado ya no es quien determina las pautas sino la misma sociedad, es tan interesante la relación social y cultural la que debe ser la base para la convivencia de todos.

Actualmente en Navojoa no se generan empleos en el mismo porcentaje de alumnos que egresan de las universidades, no hay fuentes de trabajo, teniendo que desempeñar actividades que no necesitan mano de obra calificada y ganan un poco más del salario mínimo.

Es por esto necesario aplicar el pensamiento crítico en la educación ya que presupone la observación, el conocimiento reflexivo, los compromisos, la transformación en forma personal y social y que los alumnos sean capaces de 


\section{(Edición especial julio- diciembre 2016)}

\section{http://revistainvestigacionacademicasinfrontera.com}

Revista de Investigación

Académica sin Frontera ISSN: 2007-8870

generar sus propios empleos, de transformar su realidad y hacer que se les respeten sus derechos humanos solo asi habrá democracia y si hay democracia habrá buenos ciudadanos. $Y$ si hay buenos ciudadanos habrá paz., podrá funcionar el dialogo ante los problemas.

Todos los derechos humanos son formación en valores que se inician en las familias, se deben tener fuertes raíces culturales y sería fabulosos aplicar la metodología del aprendizaje centrado en el alumno educador (yo no enseño sino los alumnos) para lo que requieren aprender habilidades especificas así como formación en valores y organizarse partiendo de las necesidades reales y verdaderas, existentes como problemática y para su solución se sugiere que los alumnos empiecen a ofrecer a la sociedad talleres donde se manejen los siguientes apartados los cuales están muy entrelazados los temas por lo que es necesarios que se conozcan para poder actuar en consecuencia y luchar por nuestra dignidad y defensa de los derechos, se sugiere trabajar por equipos en las comunidades de su entorno.

Taller de: DE LOS DERECHOS HUMANOS, LA PAZ, CIUDADANIA

I.- CONCEPTOS (AMPLIAMENTE DE LOS DERECHOS HUMANOS, LA PAZ, CIUDADANIA)

II.- DEFENSA DEL TEMA (DE LOS DERECHOS HUMANOS, LA PAZ, CIUDADANIA)

III.- SITUACION ACTUAL (DE LOS DERECHOS HUMANOS, LA PAZ, CIUDADANIA) 
IV.- EDUCACION PARA (DE LOS DERECHOS HUMANOS, LA PAZ, CIUDADANIA)

ES DERECHO DE TODOS Y DE TODAS LA PAZ CIVIL QUE INCLUYE EL DERECHO A LA SEGURIDAD Y EL DERECHO A SER PROTEGIDO CONTRA TODO ACTO DE VIOLENCIA O TERORISMO.

\section{REFERENCIAS}

COMISION NACIONAL DE DERECHOS HUMANOS, 2.-2. (s.f.).

Conde Flores, S. L. (2014). La violencia y la cultura de la calle entran a la escuela: acciones y reacciones. Revista Electróica Sinéctica, núm. 42, enero-junio, págs 1-21.

Espinosa, M. (2008). La participacion ciudadana como una relacion socio-estatal acotada por la concepcion de democracia y ciudadanía. Scielo, 30.

Garcia Ramirez, J. C. (s.f.).

Giraldo-Zuluaga, G. A. (2015,). Ciudadanía: aprendizaje de una forma de vida. Educación y Educadores, vol. 18, núm. 1, 76-92.

Gomez Johnson, C. (2014). historia y grafia . Redalyc, 219-228 .

Hernán, T. N. (2011). Las esferas del reconocimiento en la teoria de Axel Honnet. Revista de Sociología, 45-57.

Jimenez Bautista , F. (2009). Hacia un paradigma pacifico-la paz neutra. Convergencia, 141-189.

Le Barón, Julian;. (2016). El Movimiento por la Paz con Justicia y Dignidad. Mexico: Litografia Ingramex S.A. de C.V.

Lizcano Fernández, F. (2012). Conceptos de ciudadano, ciudadanía y civismo. Polis, Revista de la Universidad Bolivariana. 
Año 9. Núm. 24 (Edición especial julio- diciembre 2016)

\section{http://revistainvestigacionacademicasinfrontera.com}

Revista de Investigación

Académica sin Frontera ISSN: 2007-8870

Martinez Real, C. N. (2012). La educación para la paz como eje transversal en el nivel medio superior. RA XIMHAI, 71-91.

Mejía Jiménez , M. R. (2014). Educaciones y Pedagogías Críticas desde el sur. México: Consejo de Educacion de Adultos de America Latina.

Muñoz, V. (2014). El derecho humano a la educación. Revista Electrónica Sinéctica, núm. 42, enero-junio, 1-10.

NIEBLAS PICOS , A. (2015, 2 DE SEPTIEMBRE DE 2016). GUIA BASICA DE DERECHOS UNIVERSITARIOS. NAVOJOA.

Quiroz miranda, S. (2016). Epistemologias de la vida cotidiana escolar. Ensenada B.C.: impresora del noroeste.

Ruiz Rodriguez , V. (2007). Derechos Humanos Universales . Scielo, 155-166.

Tajonar, H. (3 de julio 2016). Educación ,Cerrázon y tragedia. Proceso, 52-53.

VARGAS DE AVELLA , M. (2007). revista iberoamericana sobre calidad, eficacia y cambio en educacion . revista iberoamericana sobre calidad, eficacia y cambio en educacion , 36-39.

Vidigal De Oliveira., A. (2011 ). tesis doctoral. . Madrid .

Vidrio, S. G. (s.f.). Ciudadania.

Vilches Choquehuayt, G., \& Ffisancho, S. H. (2013). creencias sobre los derechos humanos en estudiantes universitarios .

Vinyamata, C. E. (2015). Conflictología. Revista de Paz y Conflictos, 9-24. 